\title{
Insights into the Microstructural Evolution Occurring during Pyrolysis of Metal-Modified Ceramers Studied through Selective $\mathrm{SiO}_{2}$ Removal
}

\author{
Aitana Tamayo ${ }^{1, *(\mathbb{D}}$, Juan Rubio ${ }^{1}$, Fausto Rubio ${ }^{1}\left(\mathbb{D}\right.$ and $\mathbf{M}^{\mathrm{a}}$ Angeles Rodriguez ${ }^{2}$ \\ 1 Institute of Ceramics and Glass, CSIC, Kelsen 5, 28049 Madrid, Spain; jrubio@icv.csic.es (J.R.); \\ frubio@icv.csic.es (F.R.) \\ 2 Faculty of Science, Department of Environmental, University of Extremadura, \\ Avda. Elvas s/n, 06071 Badajoz, Spain; marodgon@unex.es \\ * Correspondence: aitanath@icv.csic.es; Tel.: +34-91-735-5840
}

Citation: Tamayo, A.; Rubio, J.; Rubio, F.; Rodriguez, M.A. Insights into the Microstructural Evolution Occurring during Pyrolysis of Metal-Modified Ceramers Studied through Selective $\mathrm{SiO}_{2}$ Removal. Materials 2021, 14, 3276. https:// doi.org/10.3390/ma14123276

Academic Editor: Juergen Stampfl

Received: 17 May 2021

Accepted: 11 June 2021

Published: 14 June 2021

Publisher's Note: MDPI stays neutral with regard to jurisdictional claims in published maps and institutional affiliations.

Copyright: (c) 2021 by the authors. Licensee MDPI, Basel, Switzerland. This article is an open access article distributed under the terms and conditions of the Creative Commons Attribution (CC BY) license (https:/ / creativecommons.org/licenses/by/ $4.0 /)$.

\begin{abstract}
Silicon oxycarbide ceramers containing 5\% aluminum, zirconium, and cobalt with respect to the total Si amount are prepared from a commercial polysiloxane and molecular precursors and pyrolyzed at temperatures ranging from 500 to $1000{ }^{\circ} \mathrm{C}$. HF etching is carried out to partially digest the silica phase, thus revealing structural characteristics of the materials, which depend upon the incorporated heteroatom. From the structural and textural characterization, it was deduced that when $\mathrm{Al}$ enters into the ceramer structure, the crosslinking degree is increased, leading to lower carbon domain size and carbon incorporation as well. On the contrary, the substitution by $\mathrm{Zr}$ induced a phase-separated $\mathrm{SiO}_{2}-\mathrm{ZrO}_{2}$ network with some degree of mesoporosity even at high pyrolysis temperatures. Co, however, forms small carbidic crystallites, which strongly modifies the carbonaceous phase in such a way that even when it is added in a small amount and in combination with other heteroatoms, this transient metal dominates the structural characteristics of the ceramer material. This systematic study of the ceramer compounds allows the identification of the ultimate properties of the polymer-derived ceramic composites.
\end{abstract}

Keywords: polymer-derived ceramics; ceramer; molecular precursors; HF etching; pyrolysis; spectroscopy

\section{Introduction}

The partial conversion of polysiloxane precursors into hybrid materials (ceramers) with high specific surface areas, tunable pore size distributions, and adjustable surface characteristics has been widely studied over the past years. The chemical and physical properties can be easily modified by using different heteroatoms, leading to the production of completely new materials with high purity and homogeneous distribution of the constituent phases. Bonding the heteroatoms to the hybrid precursor before crosslinking as well as the use of coordination compounds are the most explored methodologies for the preparation of metal-modified polymer-derived ceramics and ceramers [1]. At the early stages of research in polymers and hybrid materials for nanostructured ceramics, much effort was made on the modification of a silicon-based gel by aluminum and boron [2-4]. Since then, and despite the high potential of these materials, the majority of the studies are based on incorporating various heteroatoms with the aim of increasing the operational temperature [5]. Nanocomposites, based on silicon polymers with metallic nanoparticles, are an exciting solution, enabling the development of sensors, chemical reactors, membrane supports, or thermal insulators, among many other applications [6-9].

The different phase compositions of the SiMOC ceramers $(\mathrm{M}=\mathrm{Ti}, \mathrm{Al}, \mathrm{Zr}, \mathrm{Hf}, \mathrm{Fe}, \mathrm{Mn}$, etc.) has been demonstrated to be thermodynamically controlled by oxidation-reduction reactions, which depend on the type of heteroatom introduced into the ceramic network [10]. 
It is known that SiAlOC materials minimize the extent of the carbothermal reduction, compared to pure $\mathrm{SiOC}$ and can be employed as high-temperature pressure sensors [11,12]. The minimized amount of free carbon phase and $\mathrm{SiO}_{4}$ units, together with the formation of mullite, contribute to the reduction of the extent of the carbothermal reaction, thus permitting the development of novel high-temperature barrier resistant coatings [13]. The low activation energy of mullite formation through the polymer-derived ceramic route allows fast and quantitative crystallization of mullite at lower temperatures than the conventional methods. Moreover, its crystallization extent can be further controlled with the increase in temperature. Then, when mullite units appear, the carbon is segregated from the SiOC network via vapor-liquid-solid mechanism, producing a highly densified network, a reaction that is enhanced with the increase in the number of $\mathrm{SiC}$ units [14]. This extraordinary microstructure has been used for the development of piezoelectric ceramics in which the piezo-dielectricity of the material resulted from the formation of space charges along the interface between the relatively insulating ceramic phase and the more conductive free-carbon phase [15]. It must be highlighted that in piezoelectric materials, the presence of relatively conducting grains and insulating grain boundaries is considered to be responsible for the polarization mechanism; nevertheless, in the polymer-derived ceramics, the presence of these space charges is not yet completely understood and must be evaluated.

On the other hand, one of the first commercial applications of polymer-derived ceramics was the production of $\mathrm{SiC}$ carbon fibers; the $\mathrm{SiTiCO}$ fibers were the first-generation fibers commercialized by Ube Industries [16]. In order to reduce the oxygen content of the fibers, Ti was replaced by $\mathrm{Zr}$, leading to the consecution of improved strength retention at high temperatures. Contrary to $\mathrm{Ti}, \mathrm{Zr}$ does not usually form a TiC phase but $\mathrm{ZrO}_{2}$ instead, which afterward evolves to the $\mathrm{ZrC}$ phase, inducing enhanced thermal stability [17]. Now, the third generation of $\mathrm{SiC}$ fibers includes $\mathrm{Al}$ to help the crosslinking of the polymeric fibers.

Transition-metal-based nanoparticles ( $\mathrm{Ni}, \mathrm{Fe}$, and $\mathrm{Co}$ ) deposited over the surface of a highly porous $\mathrm{SiOC}$ and $\mathrm{SiCN}$ matrix have also been investigated as efficient metalsupported catalysts for $\mathrm{CO}_{2}$ methanation because of the selective modification of the microstructure of the obtained materials $[18,19]$. The Ni-modified, polymer-derived ceramers result in a dispersion of small nanoparticles, well distributed throughout the network, where $C$ tends to form large crystallites up to $10 \mathrm{~nm}$ when the ceramer materials are pyrolyzed at temperatures higher than $600{ }^{\circ} \mathrm{C}$, resulting in a highly hydrophilic surface with 1D nanostructures [20]. The formation of these 1D carbon nanostructures within the pores of the ceramics has also been reported by several authors $[9,21]$, showing an enhanced catalytic behavior. Co catalyst was more effective in the formation of the carbon nanostructures, increasing considerably the available specific surface area for reaction [22]. The growth mechanism depends on the included heteroatom [20,22-24].

The characterization of a silicon-based material after HF etching and subsequent oxidation allowed an increased number of the $\mathrm{SiO}_{4}$ tetrahedral to be identified, whereas the relative number of $\mathrm{SiC}_{4}$ tetrahedral diminished, indicating that the surface of the HF materials was completely heterogeneous [25]. After etching, remainders of Si-C on the surface of the graphitic carbon layers, which evolves to $\mathrm{SiO}_{2}$, turned out to be dependent on the pyrolysis temperature, thus highlighting the importance of studying the tendency to segregate $\mathrm{SiO}_{2}$ clusters during the thermal transformation [26]. The work described here aims to provide a comprehensive overview of the changes occurring during the pyrolysis of several metal-modified silicon-based ceramers, focusing on the carbon phase and the formation of the mixed SiOC network.

The selection of the heteroatoms is based on the effect these atoms exert on the microstructure. While it is known that $\mathrm{Al}$ easily incorporates into the SiOC network, forming a SiC-enriched network, Co tends to form $1 \mathrm{D}$ and $2 \mathrm{D} \mathrm{C}$ nanostructures. In addition, $\mathrm{Zr}$ is known to increase the thermal stability of the polymer-derived ceramics and the formation of $\mathrm{ZrO}_{2}$ nanoclusters, thus minimizing the number of $\mathrm{Si}$ atoms bonded to $\mathrm{O}$. Here, the evolution of the microstructure is studied in a ceramer network deficient of Si-O 
bonds because of the addition of the heteroatom $\mathrm{Zr}$. The matrix without $\mathrm{Co}$ is studied as well. Through chemical etching in a post-pyrolysis process [7,9], we have removed the $\mathrm{SiO}_{2}$ like clusters, allowing our materials to show the distinct features of the surface of the porous materials and the free carbon phase, as well as allowing the study of the main structural characteristics of the substituted networks $[27,28]$. Therefore, the final aim of the study is to provide a comprehensive overview of the changes induced in the ceramer material because of the presence of the different heteroatoms - alone and in combination - with a focus on identifying the ultimate reason for their intriguing characteristics.

\section{Materials and Methods}

Commercially available polymethylsilsesquioxane (Silres ${ }^{\circledR}$ MK powder, Wacker Chemie, Munich, Germany, empirical formula $\left(\mathrm{RSiO}_{1,5}\right)_{\mathrm{n}}$ where $\mathrm{R}=\mathrm{CH}_{3}$ and $\left.n=130-150\right)$ was used as raw material. Zirconium acetylacetonate ( $\mathrm{Zr}$ (Acac), Sigma-Aldrich, Burlington MA, USA), aluminum acetylacetonate (Al (Acac), Sigma-Aldrich, Burlington MA, USA), and cobalt acetate (CoAc, Probus, Esparraguera, Spain) were mixed with MK preceramic polymer in a planetary ball mill at $150 \mathrm{rpm}$ for $15 \mathrm{~min}$. The amount of $\mathrm{Zr}$ (Acac), $\mathrm{Al}$ (Acac), and $\mathrm{CoAc}$ was fixed in such a way that the heteroatom $/ \mathrm{Si}$ weight ratio was $5 \%$. $((\mathrm{Zr} / \mathrm{Si})=$ $(\mathrm{Al} / \mathrm{Si})=(\mathrm{Co} / \mathrm{Si})=0.05)$. Once mixed, the materials were pyrolyzed in an alumina tube furnace at a fixed heating/cooling rate of $5{ }^{\circ} \mathrm{C} / \mathrm{min}$ to temperatures between 500 and $1000{ }^{\circ} \mathrm{C}$ under a continuous nitrogen flow of $150 \mathrm{~mL} / \mathrm{min}, 5 \mathrm{~h}$ dwelling at $280^{\circ} \mathrm{C}$, plus $2 \mathrm{~h}$ at the maximum temperature. Pyrolyzed samples were ground in an agate mortar and sieved using the 100-200 micrometer fraction for all analyses and treatments. In this work, sample labeling indicates the heteroatom used (or the two of them in the case of using two modifiers together, such as $\mathrm{Zr}$ and $\mathrm{Co}$ ), followed by an $\mathrm{F}$ in the case of the etched samples.

Etching of the sieved samples was carried out by magnetic stirring in an HF solution $(40 \% \mathrm{v} / \mathrm{v})$ for $24 \mathrm{~h}$, and the resulting materials were recovered by centrifugation at $2300 \mathrm{rpm}$ for $12 \mathrm{~min}$. Etching in powdered materials was preferred rather than in bulk samples to facilitate etching. No estimation of the etching efficiency was carried out. Then, the materials were washed with distilled water until the final $\mathrm{pH}$ of the washing liquors was 5.0. Etched powders were subsequently dried at $110^{\circ} \mathrm{C}$ until constant weight.

The chemical composition was calculated from the chemical analysis carried out in elemental analyzers (LECO Corp, St Joseph MI, USA), CS-200 for the C determination, RC-420 for hydrogen content, and TC-500 to determine the oxygen amount. At least four analyses were carried out per sample and equipment, and the resulting value was calculated by average. Silicon was determined by difference. Structural characterization of the SiOC materials was carried out by means of FTIR and Raman spectroscopies. FTIR analyses were performed in a PerkinElmer (Waltham MA, USA) model BX spectrophotometer by diluting the samples in $\mathrm{KBr}$ and obtaining the spectra as the average of at least 32 collections with a spectral resolution of $2 \mathrm{~cm}^{-1}$. Raman characterization was carried out in a Renishaw InVia spectrophotometer by using the $514 \mathrm{~nm} \mathrm{Ar}^{+}$ion laser as an excitation source in the confocal mode. The spectra were the accumulated signal of 10 collections with an accumulation time of $10 \mathrm{~s}$.

Differential scanning calorimetry analyses were performed in a piece of Q600 equipment (TA Instruments, New Castel, DE, USA), using about $20 \mathrm{mg}$ of the sample under $100 \mathrm{~mL} / \mathrm{min}$ airflow. The instrument was calibrated with Aluminum and Gold for temperatures and sapphire for Heat Flow calculation.

Textural analyses were carried out in the Tristar equipment (Micromeritics, Norcross GA, USA). From the adsorption-desorption $\mathrm{N}_{2}$ isotherm, the porous properties and the specific surface area of all samples were determined by using the BJH and BET methods, respectively [29]. Prior to the analysis, all the samples were degassed at $120^{\circ} \mathrm{C}$ for $18 \mathrm{~h}$.

\section{Results}

The percentage amounts of carbon, oxygen, and hydrogen in each sample were determined to obtain the overall chemical formulae of the studied materials (Table 1). In 
these formulae, it is estimated that the weight of the heteroatom, calculated from the initial molar ratio $\mathrm{Si} / \mathrm{M}(\mathrm{M}=\mathrm{Al}, \mathrm{Zr}, \mathrm{Co})$, is maintained constantly during the pyrolysis.

Table 1. Chemical composition of the studied materials (deviation \pm 0.05 ).

\begin{tabular}{cccccc}
\hline $\left.\mathbf{T ~} \mathbf{}^{\circ} \mathbf{C}\right)$ & $\mathbf{A l}$ & \multicolumn{2}{c}{$\mathbf{Z r}$} & \multicolumn{1}{c}{ Co } & Zr/Co \\
\hline 500 & $\mathrm{SiAl}_{0.05} \mathrm{O}_{1.68} \mathrm{C}_{0.97} \mathrm{H}_{3.13}$ & $\mathrm{SiZr}_{0.02} \mathrm{O}_{1.42} \mathrm{C}_{0.94} \mathrm{H}_{2.82}$ & $\mathrm{SiCo}_{0.06} \mathrm{O}_{1.57} \mathrm{C}_{0.89} \mathrm{H}_{2.79}$ & $\mathrm{SiZr}_{0.02} \mathrm{Co}_{0.03} \mathrm{O}_{1.59} \mathrm{C}_{0.94} \mathrm{H}_{3.02}$ \\
600 & $\mathrm{SiAl}_{0.05} \mathrm{O}_{1.18} \mathrm{C}_{0.74} \mathrm{H}_{2.31}$ & $\mathrm{SiZr}_{0.02} \mathrm{O}_{1.52} \mathrm{C}_{0.86} \mathrm{H}_{2.41}$ & $\mathrm{SiCo}_{0.07} \mathrm{O}_{2.18} \mathrm{C}_{1.09} \mathrm{H}_{3.75}$ & $\mathrm{SiZr}_{0.02} \mathrm{Co}_{0.03} \mathrm{O}_{1.93} \mathrm{C}_{1.03} \mathrm{H}_{2.80}$ \\
700 & $\mathrm{SiAl}_{0.05} \mathrm{O}_{1.39} \mathrm{C}_{0.59} \mathrm{H}_{1.08}$ & $\mathrm{SiZr}_{0.02} \mathrm{O}_{1.08} \mathrm{C}_{0.58} \mathrm{H}_{1.69}$ & $\mathrm{SiCo}_{0.07} \mathrm{O}_{2.53} \mathrm{C}_{0.98} \mathrm{H}_{2.19}$ & $\mathrm{SiZr}_{0.02} \mathrm{Co}_{0.03} \mathrm{O}_{1.99} \mathrm{C}_{1.01} \mathrm{H}_{2.36}$ \\
800 & $\mathrm{SiAl}_{0.05} \mathrm{O}_{1.55} \mathrm{C}_{0.68} \mathrm{H}_{0.70}$ & $\mathrm{SiZr}_{0.02} \mathrm{O}_{1.43} \mathrm{C}_{0.73} \mathrm{H}_{1.12}$ & $\mathrm{SiCo}_{0.06} \mathrm{O}_{1.85} \mathrm{C}_{0.80} \mathrm{H}_{1.83}$ & $\mathrm{SiZr}_{0.02} \mathrm{Co}_{0.03} \mathrm{O}_{1.85} \mathrm{C}_{0.83} \mathrm{H}_{1.32}$ \\
900 & $\mathrm{SiAl}_{0.05} \mathrm{O}_{1.41} \mathrm{C}_{0.61} \mathrm{H}_{0.23}$ & $\mathrm{SiZr}_{0.02} \mathrm{O}_{1.58} \mathrm{C}_{0.65} \mathrm{H}_{1.01}$ & $\mathrm{SiCo}_{0.06} \mathrm{O}_{1.98} \mathrm{C}_{0.78} \mathrm{H}_{0.11}$ & $\mathrm{SiZr}_{0.02} \mathrm{Co}_{0.03} \mathrm{O}_{1.94} \mathrm{C}_{0.74} \mathrm{H}_{1.18}$ \\
1000 & $\mathrm{SiAl}_{0.05} \mathrm{O}_{0.68} \mathrm{C}_{0.51} \mathrm{H}_{0.04}$ & $\mathrm{SiZr}_{0.02} \mathrm{O}_{1.50} \mathrm{C}_{0.58} \mathrm{H}_{0.03}$ & $\mathrm{SiCo}_{0.07} \mathrm{O}_{2.16} \mathrm{C}_{0.85} \mathrm{H}_{0.07}$ & $\mathrm{SiZr}_{0.02} \mathrm{Co}_{0.03} \mathrm{O}_{2.35} \mathrm{C}_{0.86} \mathrm{H}_{0.04}$ \\
\hline
\end{tabular}

Figure $1 \mathrm{a}$ shows the trend of the ratio $\mathrm{O} / \mathrm{C}$, along with the pyrolysis temperature in all the materials. It is clear that this ratio varies with the elements incorporated into the ceramic network, and it should be different when using different ligands attached to the heteroatom. In contrast to the case of $\mathrm{Al}$, in which a maximum in the $\mathrm{O} / \mathrm{C}$ ratio is reached at the intermediate pyrolysis temperatures $\left(700-900{ }^{\circ} \mathrm{C}\right)$, when the heteroatom is a transition metal, a gradual increase is observed in the $\mathrm{O} / \mathrm{C}$ ratio with the increase in the pyrolysis temperature. This ratio is also slightly higher when the Co (either alone or in combination with $\mathrm{Zr}$ ) is incorporated into the preceramic network leading to a major $\mathrm{O}$ content when both the $\mathrm{Zr}$ and $\mathrm{Co}$ are introduced with respect to the Al-containing materials. Similarly, in Figure $1 \mathrm{~b}$, the composition of the materials pyrolyzed at $1000{ }^{\circ} \mathrm{C}$ is represented as a ternary diagram, in which the $\mathrm{H}$ amount has not been taken into account. There, the previous observation is observed that the incorporation of $\mathrm{Zr}$ and Co (and both elements together) induces an increase in the amount of $\mathrm{O}$ incorporated into the ceramic network at the maximum pyrolysis temperature.
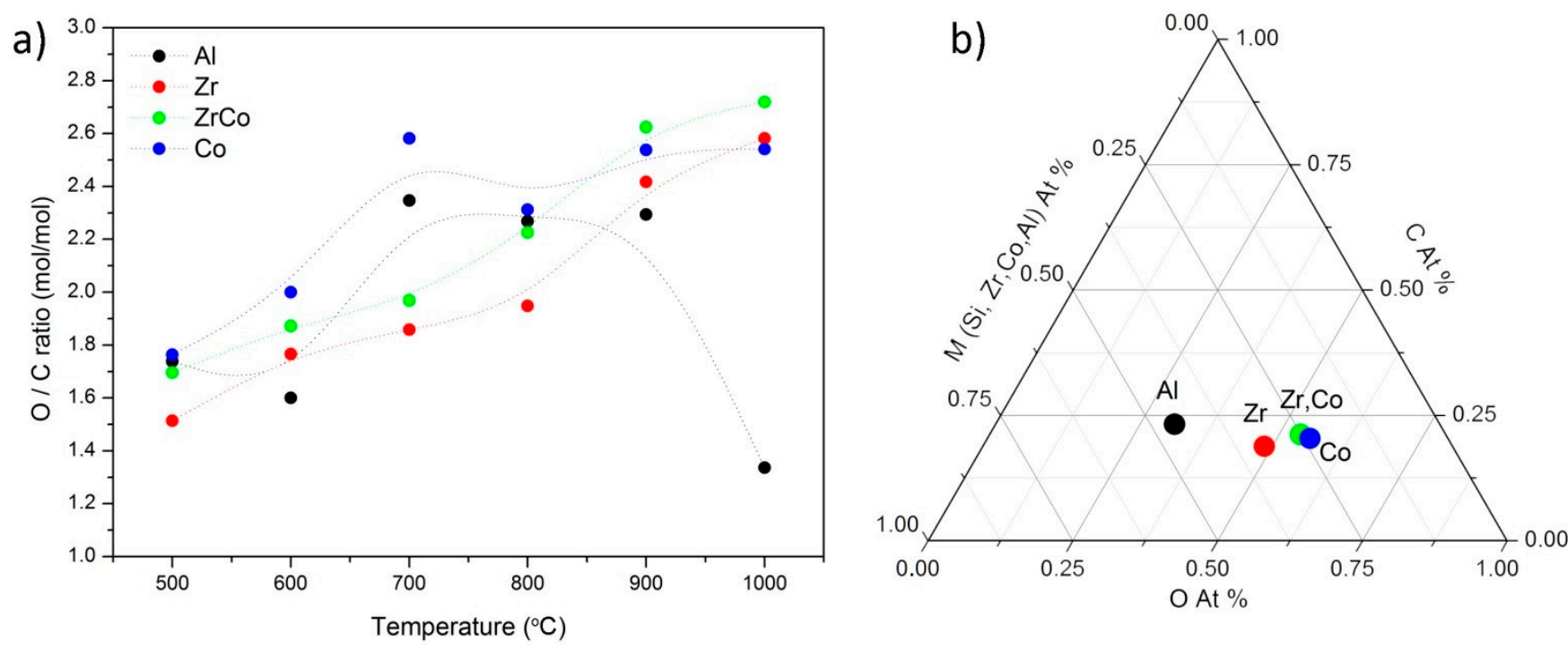

Figure 1. (a) $\mathrm{O} / \mathrm{C}$ ratio of the samples and its evolution with pyrolysis temperature (dotted lines are drawn to guide eye) and (b) ternary diagram of the samples pyrolyzed at $1000{ }^{\circ} \mathrm{C}$.

\subsection{Structural Characterization of the Ceramer Materials}

In Figure 2a, the FTIR spectra of all the samples pyrolyzed at $700{ }^{\circ} \mathrm{C}$ are plotted since at this temperature, the bands are more clearly detected. In the low-frequency region, the (O-Si-O) centered at $470 \mathrm{~cm}^{-1}$ is shifted to lower wavenumbers in the sample containing $\mathrm{Co}$, indicating a highly tensioned structure [30]. The tensioned structure contains distorted $\mathrm{O}-\mathrm{Si}-\mathrm{O}$ bond angles with respect to the normal values found in the $\mathrm{SiO}_{2}$. Since the ceramic network is partially formed, apart from the vibration of the $\mathrm{Si}-\mathrm{O}$ bonds at $790 \mathrm{~cm}^{-1}$, the 
incorporation of the mixed $\mathrm{C}-\mathrm{Si}-\mathrm{O}$ units induced the appearance of a new band centered at $810-845 \mathrm{~cm}^{-1}$, which shifts to high or low wavenumbers depending on the pyrolysis temperature and the incorporated heteroatom. Figure $2 \mathrm{~b}$ presents the position of this band calculated by means of a deconvolution analysis. Here, it is shown that when $\mathrm{Al}$ or $\mathrm{Zr}$ is added, the $\mathrm{SiOC}$ band shifts to $845-835 \mathrm{~cm}^{-1}$, at pyrolysis temperatures comprised between 700 and $900{ }^{\circ} \mathrm{C}$, and then decreases again to $810 \mathrm{~cm}^{-1}$, which is the reported position for SiOC glasses [31,32]. If the incorporated heteroatom is $\mathrm{Co}$ or $\mathrm{Zr} / \mathrm{Co}$, a gradual shift to high wavenumbers is produced when the pyrolysis is carried out up to $800{ }^{\circ} \mathrm{C}$ and then drops to $800-810 \mathrm{~cm}^{-1}$, which is considered the normal range for $\mathrm{SiO}_{2}$ and $\mathrm{SiOC}$ materials. Since the same trend is found in the two cases, it is reasonable to attribute the observed behavior to the presence of the Co. At $1000^{\circ} \mathrm{C}$, in the sample containing the two heteroatoms, the position of this band decreases to its lowest value, possibly due to phase separation.

a)

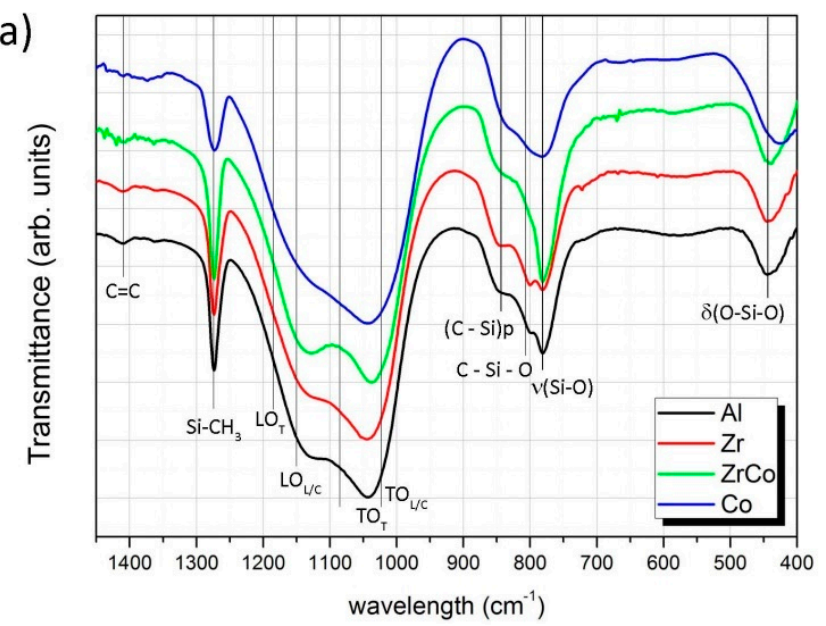

c)

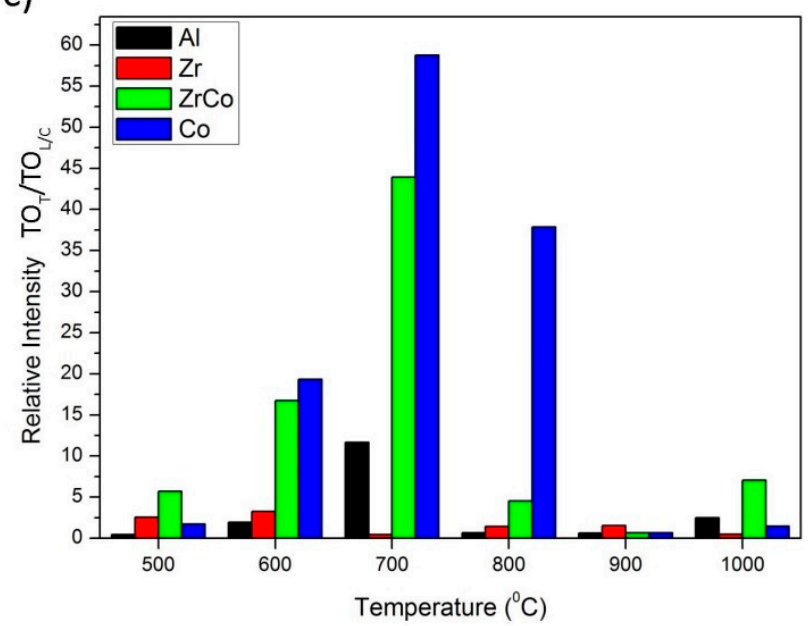

b)

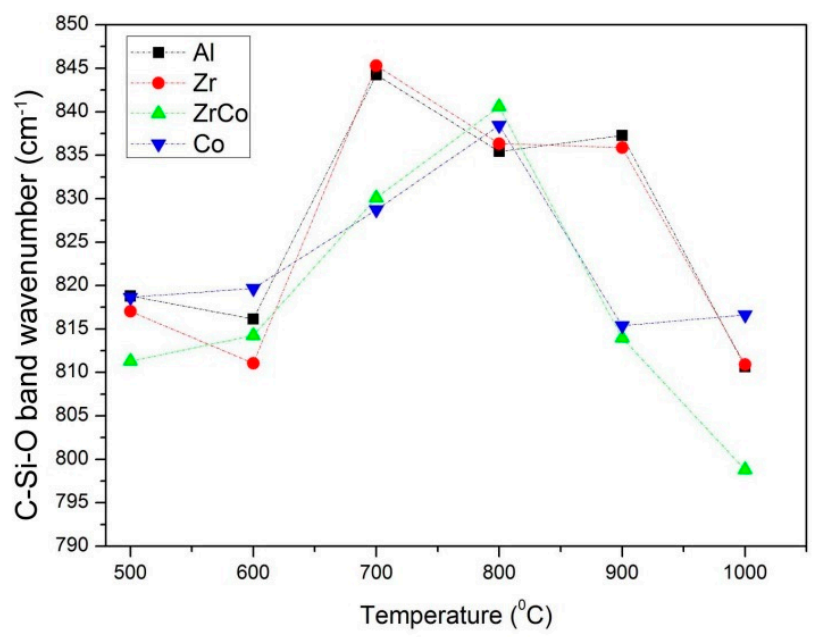

d)

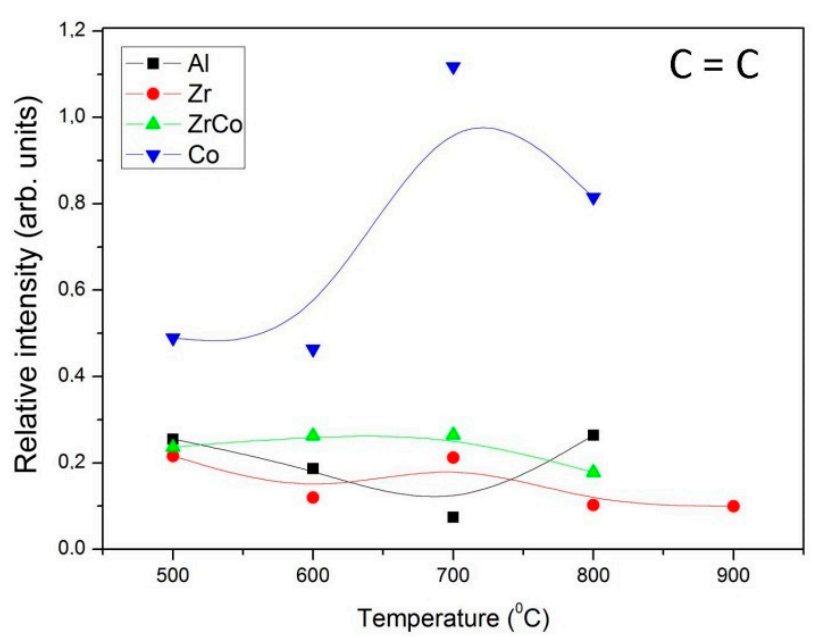

Figure 2. (a) FTIR spectra of the samples pyrolyzed at $700{ }^{\circ} \mathrm{C} ;(\mathbf{b})$ position of the band corresponding to the formation of $\mathrm{SiOC}$ bonds as a function of the temperature; (c) relative intensity ratio of the bands assigned to the stretching mode of the superstructural rings forming tridimensional $(\mathrm{T})$ and chains $(\mathrm{L} / \mathrm{C})$; $(\mathbf{d})$ relative intensity of the bands assigned to the asymmetric stretching of double-bonded carbon. This intensity was normalized to the area of the band at $1080 \mathrm{~cm}^{-1}$.

The position and intensities of the IR bands vary with both the pyrolysis temperature and the incorporation of the heteroatom. A systematic study of the infrared spectra is carried out by performing the deconvolution analysis of the bands appearing in the spectra of all the studied samples (spectra shown in Supplementary Material Figure S1). In the 
most intense region of the spectra, it is possible to distinguish the multiple combinations of the $\mathrm{Si}-\mathrm{O}$ rings and $\mathrm{Si}-\mathrm{O}-\mathrm{X}[33,34]$, where $\mathrm{X}$ can be substituted by the heteroatom symbol. In this region, the band attributed to the stretching of $\mathrm{Si}-\mathrm{O}$ bonds presents the highest relative intensity in the materials containing $\mathrm{Al}$, followed by the materials containing $\mathrm{Zr}$. This band is composed of the contribution of crosslinked $\mathrm{SiO}_{4}$ tetrahedral (tridimensional) and $\mathrm{SiO}_{2}$-like tetrahedral in form of $\mathrm{SiO}_{2}$ rings and chains. In the spectra, the band located at $1030 \mathrm{~cm}^{-1}$ is attributed to the ring-like superstructural units $\left(\mathrm{TO}_{\mathrm{L} / \mathrm{C}}\right.$ transversal optic), and the tridimensional $\left(\mathrm{TO}_{\mathrm{T}}\right.$ transversal optic) $\mathrm{SiO}_{2}$ structures appeared at about $1080 \mathrm{~cm}^{-1}$ [35-37]. The plot of the relative intensity of the tridimensional $\mathrm{SiO}_{2}$ structures (TOT, $\left.1080 \mathrm{~cm}^{-1}\right)$ to ring-like superstructural units $\left(\mathrm{TO}_{\mathrm{L} / \mathrm{C}}, 1030 \mathrm{~cm}^{-1}\right)$ is shown in Figure 2c, and it is observed that the relative intensity of this ratio undergoes low variations when either $\mathrm{Al}$ or $\mathrm{Zr}$ is incorporated into the hybrid network, but it dramatically increases when $\mathrm{Co}$ (and Co plus $\mathrm{Zr}$ ) atoms are added at pyrolysis temperatures below $800^{\circ} \mathrm{C}$ and then decreases. It should also be noticed that in the case of the $\mathrm{Al}$ incorporation, this band increases progressively up to $700{ }^{\circ} \mathrm{C}$ and afterward decreases.

When the ceramic structure is not yet formed (low pyrolysis temperature), it is possible to appreciate the asymmetric stretching of vinyl groups at $1410 \mathrm{~cm}^{-1}[38,39]$ (Figure 2d). This band is the most noticeable in the samples containing Co because of the formation of highly graphitized carbon structures at $700-800{ }^{\circ} \mathrm{C}[40,41]$. Beyond $900{ }^{\circ} \mathrm{C}$, none of the samples except the one containing $\mathrm{Zr}$ present this characteristic feature.

For a better understanding of the structural characteristics of the materials and their evolution toward the ceramic state during the pyrolysis, we subject the samples to a chemical etching to remove the major part of the $\mathrm{SiO}_{2}$ phase. The Gaussian deconvolution of the FTIR spectra of the etched samples. Figure $3 a$ is used to estimate the stability of the different ring-like or tridimensional $\mathrm{SiO}_{2}$ structures against the etching process. As we proceed with the un-etched samples, here (Figure $3 b$ ) we only show the spectra of the bands pyrolyzed at $900{ }^{\circ} \mathrm{C}$ because the contributions to the different bands are more evident. Despite that, it should also be noted here that we have performed the analysis on the samples pyrolyzed and $\mathrm{HF}$ etched at temperatures beyond $800^{\circ} \mathrm{C}$. By comparing Figures $2 \mathrm{c}$ and $3 \mathrm{~b}$, the relative intensity of the $\mathrm{TO}_{\mathrm{T}}$ to $\mathrm{TO}_{\mathrm{L} / \mathrm{C}}$ bands drastically decreases in all samples and at all the treatment temperatures, indicating that the tridimensional $\mathrm{SiO}_{2}$ is more susceptible to be etched away. The most dramatic change in the $\mathrm{TO}_{\mathrm{T}} / \mathrm{TO}_{\mathrm{L} / \mathrm{C}}$ ratio is found in the samples containing Co in which the relative proportion of tridimensional units in the HF-etched samples decreases with the temperature. In the remainder materials, there is no relationship between the pyrolysis temperature and the amount of linear and tridimensional $\mathrm{SiO}_{2}$ before and after $\mathrm{HF}$ etching $\left(\left(\mathrm{TO}_{\mathrm{T}} / \mathrm{TO}_{\mathrm{L} / \mathrm{C}}\right)_{\text {pyrolyzed }} /\left(\mathrm{TO}_{\mathrm{T}} / \mathrm{TO}_{\mathrm{L} / \mathrm{C}}\right)_{\mathrm{HF} \text { etch }}\right)$.

The effect of the HF etching is also observed in the carbon phase, as deduced from Raman spectroscopy (spectra shown in Supplementary Material Figure S2). In Figure 4a, the characteristic Raman spectra of the HF-etched materials pyrolyzed at $900{ }^{\circ} \mathrm{C}$ is shown, with the $\mathrm{D}$ band appearing at $1350 \mathrm{~cm}^{-1}$, which is commonly attributed to the $\mathrm{A}_{1 \mathrm{~g}}$ mode of the small graphite crystallites, and the $\mathrm{G}$ band, which is related with the in-plane bond stretching of $\mathrm{sp}^{2}$ bonds ( $\mathrm{E}_{2 \mathrm{~g}}$ mode) in carbon clusters [42]. Similar spectra are obtained for all the remaining samples. Here, it is clearly observed that the $D$ and $G$ bands become narrower in the materials containing $\mathrm{Zr} / \mathrm{Co}$ and $\mathrm{Co}$, indicating that the remainder carbon phase after the etching process is the more graphitized. In the spectra of the as-pyrolyzed samples, the $I_{D} / I_{G}$ ratio (Figure $4 b$ ) varies with both the temperature and the included heteroatom. For the calculations, and for considering the intensity of the band (I), we use the height of the Lorentzian-shaped band obtained from the deconvolution analysis, and background subtraction is carried out before the band deconvolution. In the case of the incorporation of $\mathrm{Al}$ and $\mathrm{Zr}$, the $\mathrm{I}_{\mathrm{D}} / \mathrm{I}_{\mathrm{G}}$ ratio decreases with the temperature (i.e., the carbon phase becomes more "ordered"), whereas the incorporation of Co and $\mathrm{Zr} /$ Co provokes the opposite effect, with a decrease of the ordering of the carbonaceous phase. After etching, however, there is a slight increase in the $\mathrm{I}_{\mathrm{D}} / \mathrm{I}_{\mathrm{G}}$ ratio with the temperature when the heteroatom incorporated is $\mathrm{Al}$. Since the $\mathrm{D}$ band only accounts for $\mathrm{sp}^{2}$ rings, the observed 
increase suggests that, during etching, both the $\mathrm{C}$ atoms in $\mathrm{sp}^{2}$ and $\mathrm{sp}^{3}$ configurations were etched away.

a)

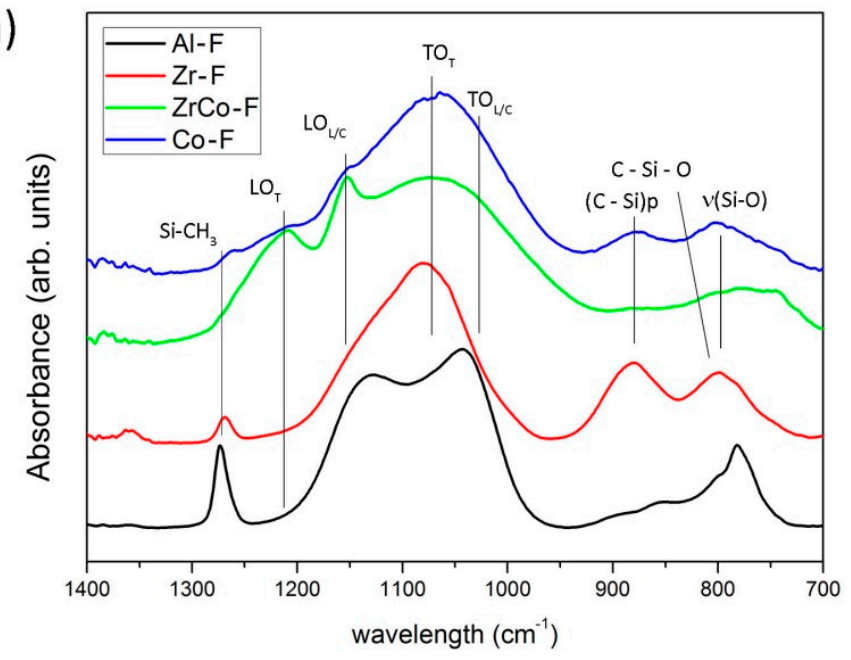

b)

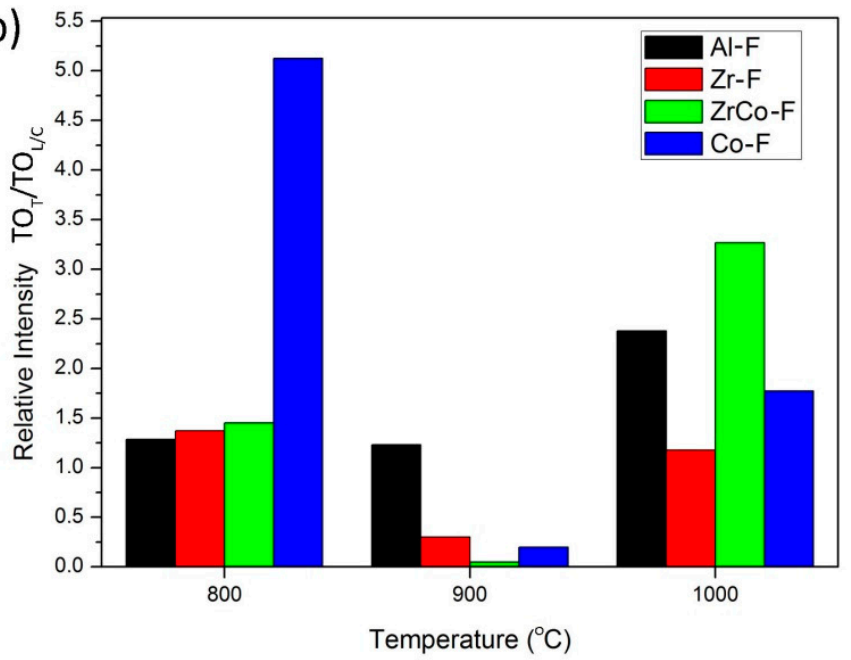

Figure 3. (a) FTIR spectra (in the absorbance mode) of the HF samples pyrolyzed at $900{ }^{\circ} \mathrm{C}$ and (b) the relative intensity ratio of the $\mathrm{TO}_{4} / \mathrm{TO}_{6}$ modes of the HF-etched samples.

a)

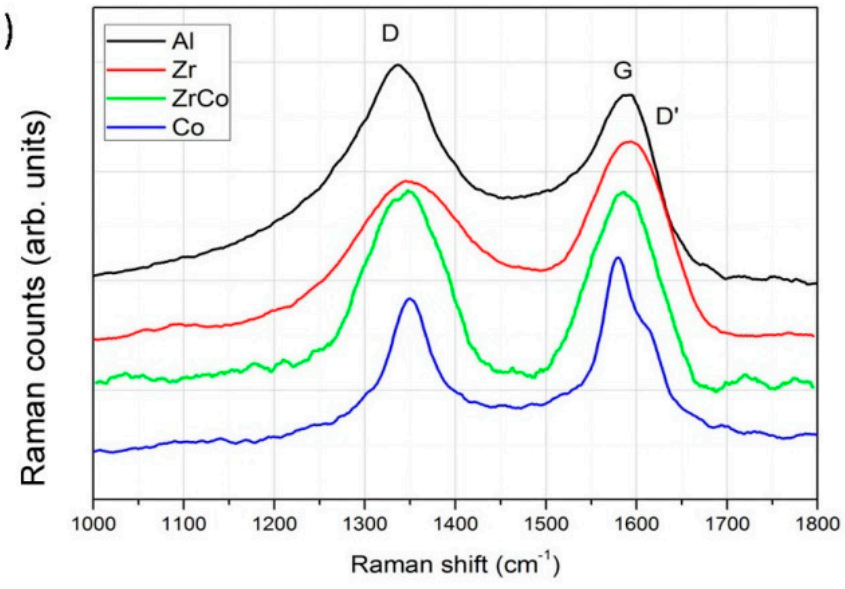

b)

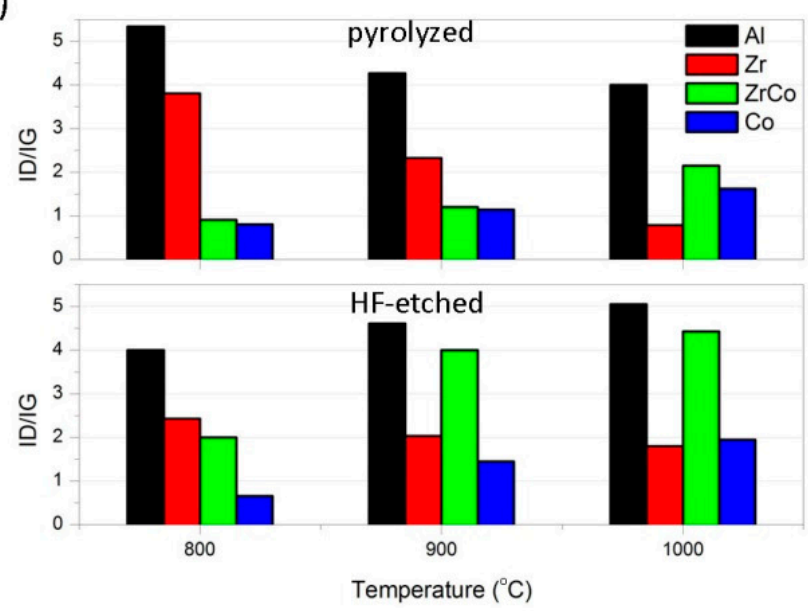

Figure 4. (a) Raman spectra of the samples pyrolyzed at $900{ }^{\circ} \mathrm{C}$; (b) relative intensity of the $\mathrm{D}$ and $\mathrm{G}$ bands (ID/IG) of the Raman spectra of the pyrolyzed and HF-etched materials.

\subsection{Thermal Analysis}

Valuable information about the carbon phase can be obtained when studying the thermal stability in the air, both before and after the etching treatment. The different behavior shown in all the samples is quite significant, with different decomposition temperatures and the number of decomposition stages depending on the substituent heteroatom (Figure 5a). The most characteristic temperatures during the oxidation of the materials are collected in Table 2 (differential thermal analysis curves are found in Supplementary Material Figure S3). There, it should be noticed that despite the inorganic material is not formed (the materials are still in ceramer state), we are carrying out the decomposition in an oxidant atmosphere, i.e., preferentially the carbon phase. Solely in the materials containing $\mathrm{Al}$ and pyrolyzed at the different temperatures, the thermal decomposition occurs in a single step, at temperatures increasing from 450 to $650^{\circ} \mathrm{C}$, as the pyrolysis temperature increases. The samples containing $\mathrm{Zr}$ as the single heteroatom decompose 
in a single step when the materials are heat treated at temperatures beyond $700{ }^{\circ} \mathrm{C}$, but two decomposition stages are found when they are pyrolyzed at $600^{\circ} \mathrm{C}$. By substituting the heteroatom for $\mathrm{Co}$, now we can observe that the number of decomposition stages as well as the temperatures at which these reactions take place, depending upon the pyrolysis temperature. In Table 2, however, the most prominent peaks are exclusively collected.
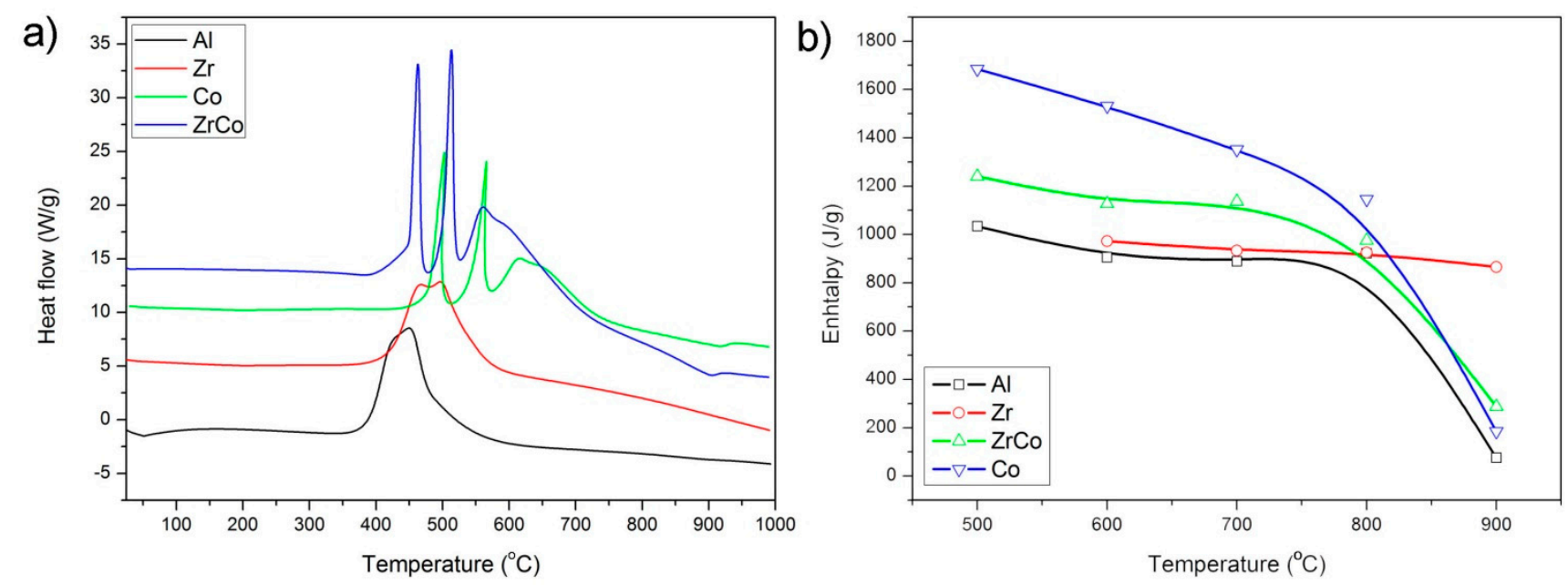

Figure 5. (a) Differential scanning calorimetry curves of the materials pyrolyzed at $600{ }^{\circ} \mathrm{C}$; (b) oxidation enthalpy.

Table 2. Temperatures $\left({ }^{\circ} \mathrm{C}\right)$ of the decomposition of the materials when heat treated in air atmosphere (n/d stands for none determined).

\begin{tabular}{|c|c|c|c|c|c|c|c|c|c|c|c|c|c|}
\hline \multirow{3}{*}{$\frac{\mathrm{T}\left({ }^{\circ} \mathrm{C}\right)}{600}$} & \multicolumn{3}{|c|}{ Al } & \multicolumn{3}{|c|}{$\mathrm{Zr}$} & \multicolumn{4}{|c|}{ Co } & \multicolumn{3}{|c|}{$\mathrm{Zr} / \mathrm{Co}$} \\
\hline & \multirow{2}{*}{$\frac{\text { Pyr }}{450}$} & \multirow{2}{*}{\multicolumn{2}{|c|}{$\frac{\text { HF Etch }}{\mathrm{n} / \mathrm{d}}$}} & \multicolumn{2}{|c|}{ Pyr } & \multirow{2}{*}{$\frac{\text { HF Etch }}{\mathrm{n} / \mathrm{d}}$} & \multicolumn{2}{|c|}{ Pyr } & \multicolumn{2}{|c|}{ HF Etch } & \multicolumn{2}{|c|}{ Pyr } & \multirow{2}{*}{$\frac{\text { HF Etch }}{\mathrm{n} / \mathrm{d}}$} \\
\hline & & & & 465 & 495 & & 465 & 515 & & & 500 & 565 & \\
\hline 700 & 495 & & & & & $\mathrm{n} / \mathrm{d}$ & 470 & 600 & & & 525 & 575 & $\mathrm{n} / \mathrm{d}$ \\
\hline 800 & 545 & & & & & $\mathrm{n} / \mathrm{d}$ & 550 & 585 & & & 545 & 600 & 535 \\
\hline 900 & 650 & 355 & 550 & & & 525 & & & 520 & 575 & 480 & & 545 \\
\hline
\end{tabular}

The calculation of the oxidation enthalpy of the materials from the DSC curves (Figure 5b and Supplementary Material Figures S3 and S4) allows the detection of the slight decrease in the decomposition enthalpy at pyrolysis temperatures below $800{ }^{\circ} \mathrm{C}$, and then a severe decrease occurs at $900{ }^{\circ} \mathrm{C}$. Oxidation enthalpy is calculated from the area under the DSC curve. This behavior is observed in the samples containing $\mathrm{Al}$ and Co but not in the materials containing $\mathrm{Zr}$ in which the oxidation enthalpy does not show significant variations among them.

\subsection{Textural Characterization}

It is well known that in most polymer-derived ceramics, transient porosity created in the intermediate stages of the pyrolysis (i.e., in the ceramer state) and associated with the elimination of gaseous species evolving from the decomposition of the preceramic matrix $\left(\mathrm{CH}_{4}, \mathrm{H}_{2}, \mathrm{C}_{6} \mathrm{H}_{6}\right.$, etc.) [43]. This transient porosity is observed in all the synthesized materials. Table 3 summarizes the specific surface area of the pyrolyzed materials from the application of the BET method to the nitrogen adsorption isotherms. In all the materials, except in the case of the samples containing $\mathrm{Zr}$ as the unique heteroatom, this transient porosity disappears at $900^{\circ} \mathrm{C}$. 
Table 3. Specific surface area of the studied materials as obtained from the BET method applied to the nitrogen adsorption isotherms (the asterisk in $\mathrm{Co}^{*}$ refers to already published data reprinted from [44] with permission from Elsevier).

\begin{tabular}{ccccc}
\hline \multicolumn{5}{c}{ SSA m ${ }^{2} / \mathrm{g}$} \\
\hline $\mathrm{T}\left({ }^{\circ} \mathrm{C}\right)$ & $\mathrm{Al}$ & $\mathrm{Zr}$ & $\mathrm{Co}^{*}$ & $\mathrm{Zr} / \mathrm{Co}$ \\
\hline 500 & 220 & 40 & 190 & 60 \\
600 & 370 & 390 & 475 & 165 \\
700 & 320 & 325 & 335 & 360 \\
800 & 265 & 270 & 255 & 290 \\
900 & 3.0 & 243 & 2.3 & 2.0 \\
1000 & 0.5 & 100 & 0.5 & 3.5 \\
\hline & & $\mathrm{SSA} \mathrm{m}^{2} / \mathrm{g}$ after HF etching & & - \\
700 & - & 1.2 & 2.0 & - \\
800 & - & 41 & 43 & 17 \\
\hline 900 & 91 & 3.3 &
\end{tabular}

The t-plot method [29] application to the $\mathrm{N}_{2}$ adsorption isotherms allows the calculation of the external surface (or area corresponding to the mesopores) from the slope of the t-plot (t-plots are provided in Supplementary Material Figure S5). In Figure 6a, it is observed that the maximum external surface corresponds to the samples pyrolyzed at $600{ }^{\circ} \mathrm{C}$ and containing $\mathrm{Al}$ and $\mathrm{Co}$, whereas, in the presence of $\mathrm{Zr}$, there is a delay in the appearance of this porosity, which is attributed to enhanced preceramic network stability. With regard to the micropore surface area (Figure $6 \mathrm{~b}$ ), apart from the abovementioned porosity still remaining at $1000{ }^{\circ} \mathrm{C}$ in the material synthesized with $\mathrm{Zr}$, it can be observed that the amount of micropores gradually increases, reaching the maximum at $700{ }^{\circ} \mathrm{C}$. In the case of Co-containing samples, the increase of the microporosity to its maximum value occurs in a more drastic manner, and the temperature at which this maximum microporosity appears is different whether the sample is synthesized in the presence or the absence of $\mathrm{Zr}$.
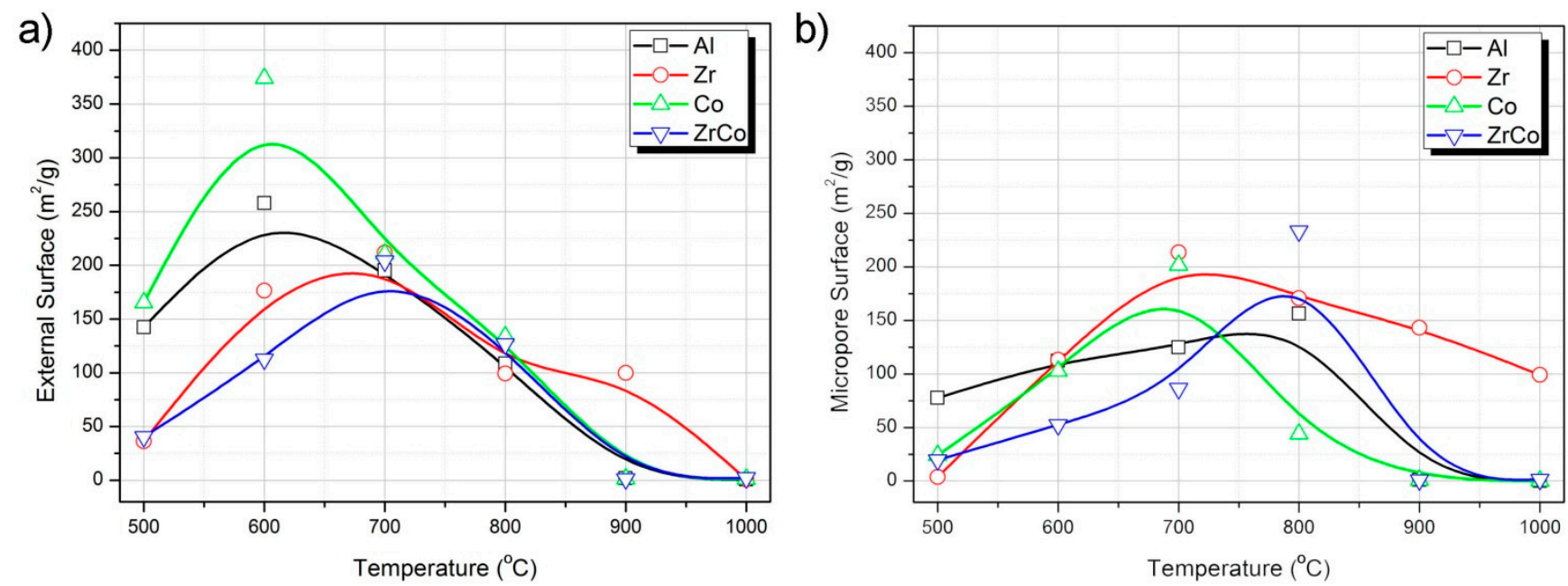

Figure 6. Surface area of the materials corresponding to (a) mesopores and (b) micropores.

Table 3 also includes the specific surface area of some of the HF-etched materials. It is observed that the material presenting the highest SSA at $900{ }^{\circ} \mathrm{C}$ is the one synthesized with the heteroatom $\mathrm{Al}$, with this SSA being even higher than in the corresponding pyrolyzed sample. The same occurs in the Co-containing material pyrolyzed at $900{ }^{\circ} \mathrm{C}$, where the SSA corresponding to the HF-etched sample is higher than its non-etched counterpart. The pore size distributions calculated from the application of the $\mathrm{BJH}$ method to the desorption branch of the isotherms obtained in the HF-etched materials are provided in Supplementary 
Material Figure S6. This behavior is attributed to the elimination of the stabilization of the $\mathrm{SiO}_{2}$ clusters, which favors phase separation and therefore the elimination of this component in the HF process. In the case of the $\mathrm{Zr}$-containing materials, a pronounced decrease in the SSA is observed after the digestion process.

\section{Discussion}

Generally, the description of the structural changes induced by the heteroatoms within the hybrid network assumes a random and homogeneous distribution of the elements. The change in the pore volume occurring after the HF etching and attributed to the removal of some disordered C and SiOC units has already been reported [45]. The discontinuous distribution of the different phases because of the presence of the different heteroatoms is thus responsible for the observed variations in the ratio of the $\mathrm{SiO}_{2}$-like structure after the $\mathrm{HF}$ etching as well as the graphitization of the carbon phase.

It is known that during pyrolysis, $\mathrm{Al}$ is able to form the $\mathrm{AlO}_{\mathrm{x}} \mathrm{C}_{\mathrm{y}}$ at a relatively low temperature through the reaction of the $\mathrm{Al}(\mathrm{OH})_{3}$ particles, which are dispersed within the ceramer network with the free carbon, thus decreasing the amount of free carbon and the observed decrease in the $\mathrm{O} / \mathrm{C}$ ratio at temperatures beyond $800{ }^{\circ} \mathrm{C}$ [2]. Moreover, the condensation mechanism of the Al-containing samples occurs via dehydrogenation reactions [46,47] with the formation of the $\mathrm{C}=\mathrm{C}$ bonds at $700{ }^{\circ} \mathrm{C}$ (Figure 2d) [48]. At this temperature, the relative intensity of the $\mathrm{TO}_{\mathrm{T}} / \mathrm{TO}_{\mathrm{LC}}$ band is the highest as well. Zhang et al. [49] report the formation of Si-O-Al bridges during the pyrolysis at the expense of the Si-H bonds. At this temperature, and accompanied with the decrease of the $\mathrm{Si}-\mathrm{H}$ band in the FTIR spectra $\left(2100 \mathrm{~cm}^{-1}\right)$, the position of the Si-O-C band is shifted from $817 \mathrm{~cm}^{-1}$ to its maximum value, at $845 \mathrm{~cm}^{-1}$, which is assigned to the symmetric stretching vibration of the Si-O-Si and Si-O-Al linkages [50]. The enhanced crosslinking at lower temperature with respect to the non-modified polysiloxane has already been described by many other authors, resulting in an increased proportion of highly crosslinked $\mathrm{SiO}_{2}$ (tridimensional) units [51,52]. This resulted in an increased intensity of the band centered at about $1100 \mathrm{~cm}^{-1}$, which contains the different modes of the Si-O-Si bonds (Figure 2a). In the HF-etched samples, the $\mathrm{TO}_{\mathrm{T}}$ to $\mathrm{TO}_{\mathrm{L} / \mathrm{C}}$ ratio decreases with respect to their corresponding non-etched counterparts indicating that the $\mathrm{SiO}_{2}$ units, which were preferentially etched, are the ones in interconnected rings or chains. This result can be further corroborated from the SSA obtained after HF etching (Table 3). At $900{ }^{\circ} \mathrm{C}$, there might be a large number of interconnected rings or chains that are preferably removed during the etching, leading to the appearance of large voids and thus increasing the SSA.

The decrease in the graphite nanodomain size of the pyrolyzed samples is attributed to the rearrangement of distorted aromatic carbon rings to six-membered rings [53]. However, after etching, the behavior of the $\mathrm{I}_{\mathrm{D}} / \mathrm{I}_{\mathrm{G}}$ ratio is exactly the opposite, suggesting that etching preferably affects the $\mathrm{sp}^{3}$ carbon. The differential thermal analysis data (Figure 5) show that the decomposition of the carbon phase occurs in just one single step, indicating that there are no secondary carbon phases evolving from this material and, as expected, the temperature at which this decomposition takes place gradually increases as the treatment temperature does. The decrease in the free-carbon phase content because of the cationic substitution of $\mathrm{Si}$ by $\mathrm{Al}$ atoms might be also responsible for the minimum oxidation enthalpy [48]. The presence of one type of carbon and the substitution of Si by Al atoms might cause the space charges and thus the polarization of the structure upon determined pressure and, ultimately, its piezoelectric behavior. This piezo-dielectricity of the material results from the formation of space charges along the interface between the relatively insulating ceramic phase and the more conductive free-carbon phase [15].

$\mathrm{SiOC}$ structural units are formed at temperatures as low as $700{ }^{\circ} \mathrm{C}$ either when the substituent heteroatom is $\mathrm{Al}$ or $\mathrm{Zr}$; however, when the $\mathrm{Zr}$ is the heteroatom, some authors have reported that the relative amount of $\mathrm{SiC}$ units decreases with the Zr content [54]. Contrary to what occurs in Al- or Ti-containing SiOC glasses, during pyrolysis, it has been reported that amorphous $\mathrm{ZrO}_{2}$ clusters are segregated from the matrix [54]. In all the 
remaining samples, the $\mathrm{TO}_{\mathrm{T}} / \mathrm{TO}_{\mathrm{L} / \mathrm{C}}$ ratio reaches a maximum of $700{ }^{\circ} \mathrm{C}$, but the opposite trend is found in the $\mathrm{Zr}$-modified SiOC. The phase separation occurring in these materials would be responsible for the decrease in Si-O-C formation and therefore, in the spectra of the HF samples (Figure 3a); we particularly highlight the presence of a single peak in the central band of the spectra because of the non-etched $\mathrm{SiO}_{2}$ units.

During the synthesis of $\mathrm{SiOC} / \mathrm{Zr}$ materials, the added $\mathrm{Zr}$ may act as an inert or active filler whenever the $\mathrm{ZrO}_{2}$ nanoclusters are already formed, or the $\mathrm{ZrO}_{2}$ are added as additional particles. Ionescu et al. [55] report that the porosity of the obtained materials increases with the addition of $\mathrm{Zr}$. On contrary, when the $\mathrm{Zr}$ source is an active substance such as the $\mathrm{Zr}$ alkoxide, the porosity dramatically decreases because of the crosslinking effect of the heteroatom [55]. Acetylacetonate, however, is a complexing agent that hinders the formation of the mixed oxycarbide structure with a preference for an early formation of amorphous $\mathrm{ZrO}_{2}$ nanoclusters [56]. Some authors also report that the maintenance of the mesoporous structure even at pyrolysis temperatures of $1000^{\circ} \mathrm{C}$ can be attributed to the decomposition of the $\mathrm{Zr}$ (Acac) used as a precursor, which was unable to form a mixed network with the polysiloxane [57]. The maintenance of the microporosity at high temperature in this work is attributed to the already observed phase separation, occurring together with the decrease of the $\mathrm{Si}-\mathrm{O}-\mathrm{C}$ bonds. The formation of a highly interconnected tridimensional network between the $\mathrm{SiO}_{2}$ and $\mathrm{ZrO}_{2}$ nanoclusters might also be responsible for the delay in the appearance of the transient micro-mesoporosity and the observed constant mesopore volume at temperatures beyond $700{ }^{\circ} \mathrm{C}$ [58]. The minimum content of $\mathrm{Si}-\mathrm{O}-\mathrm{C}$ bonds also prevents pore collapse and thus the appearance of micropores even at high pyrolysis temperature. In addition, this highly interconnected microporous network almost disappears after the HF etching (Table 3), suggesting that the $\mathrm{ZrO}_{2}$ nanoclusters could be somehow lixiviated in the digestion process because of the strong binding to the $\mathrm{SiO}_{2}$ domains.

In addition, some authors have reported that the presence of the $\mathrm{ZrO}_{2}$ units inhibits the graphitization degree of the free carbon in SiZrOC materials [59]. In our materials, despite the decreased $\mathrm{I}_{\mathrm{D}} / \mathrm{I}_{\mathrm{G}}$ ratio in the pyrolyzed samples, after etching, this ratio remains constant at all the pyrolysis temperatures. Similarly, the combustion enthalpy of the carbon phase does not alter with the temperature, suggesting that there are no further changes in the free-carbon phase configuration. Liu et al. [59] suggest that the thermal stability of the $\mathrm{Si}-\mathrm{C}$ bond is decreased in the presence of $\mathrm{Zr}$, and therefore, the cleavage of these bonds during the redistribution reaction is facilitated.

One of the most remarkable characteristics of the spectra of the Co-containing materials is the large intensity of the band assigned to $C=C$ bonds (Figure $2 \mathrm{~d}$ ). Although it is still noticeable, this effect is not so evident when both the $\mathrm{Zr}$ and Co are introduced into the preceramic matrix. In the HF-etched samples, the same behavior is repeated, with a significant increase of the $\mathrm{SiO}_{2}$ interconnected in rings or chains (Figure 3b). In both cases, either when the Co is introduced alone or together with $\mathrm{Zr}$, the $\mathrm{I}_{\mathrm{D}} / \mathrm{I}_{\mathrm{G}}$ ratio increases with the temperature either before or after etching. Here, we should consider the origin of the $\mathrm{D}$ band, which is attributed to the breathing mode of $\mathrm{sp}^{2}$ rings located at the edge of the graphite planes [60] and, as mentioned before, it becomes narrower due to the wet-etching process.

It is also known that Co forms a solid solution with $\mathrm{Si}$, resulting in nucleation sites for the $\mathrm{SiC}$ crystallization at high temperatures [61]. As mentioned above, contrary to $\mathrm{Zr}$, which preferably forms $\mathrm{ZrO}_{2}$ nanoclusters, large Co crystallites appearing in Co-containing $\mathrm{SiOC}$ direct the microstructural characteristics of these samples [20,61]. The XRD patterns showing the formation of these crystals are shown in Supplementary Material Figure S6. The multiple decomposition steps appearing in the DSC thermograms are attributed to crystalline cobalt carbides, which are not etched away [44]. In the presence of $\mathrm{Zr}$, the temperature at which this decomposition takes place is slightly higher than in the case of Co alone and, as we observe in the Supplementary Material Figure S3, the multiple carbidic forms are well revealed, suggesting that the $\mathrm{ZrO}_{2}$ nanoclusters that are formed 
from the decomposition of the $\mathrm{Zr}$ (acac) act as a protective phase for the stabilization of the unstable carbides.

\section{Conclusions}

HF etching results in a quite convenient strategy to study the structural changes occurring during the pyrolytic conversion of a polymeric or hybrid material subjected to any molecular modification. Nevertheless, it should be kept in mind which phases are more susceptible to the chemical etching and the structural changes induced by this treatment. The systematic study of these changes in a series of metal-modified polymerderived materials allowed us to find that the highly interconnected tridimensional units in the $\mathrm{SiO}_{2}$ phase are the most susceptible to wet etching in such a way that the materials that are more favorable to produce this sort of arrangements will also be more attacked by fluorine. In a similar fashion, the carbon atoms located near these structures will also be etched away, thus provoking some changes in the remainder carbon phase.

By introducing $\mathrm{Al}$ atoms into the structure, AlOC bonds are formed even at low temperatures, thus increasing the crosslinking degree of the preceramic network. The $\mathrm{I}_{\mathrm{D}} / \mathrm{I}_{\mathrm{G}}$ ratio after etching increases with the pyrolysis temperature, whereas if no further treatment is performed, the trend of this ratio is exactly the opposite, suggesting that etching preferably affects the $\mathrm{sp}^{3}$ carbon. The formation of the tridimensional network formed by substitution of some Si atoms by Al, together with the presence of one type of carbon, might be responsible for the piezoelectric properties reported for this material. In the case of $\mathrm{Zr}$ incorporation, the relative amount of $\mathrm{SiC}$ units decreases with the $\mathrm{Zr}$ content because of the occurrence of phase separation during pyrolysis and the carbon phase almost shows no variation in its graphitization degree. The elimination of the $\mathrm{SiO}_{2}$ phase after HF etching occurs preferentially in these $\mathrm{SiO}_{2}$ clusters, arranged in a tightly interconnected tridimensional network, increasing the well-known thermal stability of the SiZrOC materials. Contrary to what occurs in the remainder metal-modified materials, the combustion enthalpy of the carbon phase remains constant at all the temperatures because of this increased thermal stability. In view of the Raman spectra, this carbon phase seems to be the more amorphous among all the prepared materials. The complexation effect of the acetylacetonate is also noticeable here since a delay in the formation of the transient mesoporosity is observed as well as the maintenance of the porous structure at the highest pyrolysis temperature.

Another area that has been investigated is the effect of incorporating a transition metal capable of forming a solid solution with Si together with $\mathrm{Zr}$. In this case, the formation of small Co nanocrystals and the enhancement of the $\mathrm{C}=\mathrm{C}$ bonds are the main characteristics of these materials. The oxidant decomposition of the carbon phase occurs in different stages depending on the pyrolysis temperature, indicating the transition of the carbon phase from low to high graphitization. Similarly, the trend of the $\mathrm{I}_{\mathrm{D}} / \mathrm{I}_{\mathrm{G}}$ ratio with the temperature before and after etching confirms the higher graphitization degree induced by the cobalt despite the presence of the $\mathrm{Zr}$ and its amorphization effect on the free-carbon phase.

Supplementary Materials: The following are available online at https: / www.mdpi.com/article/ 10.3390/ma14123276/s1, Figure S1: Infrared spectra of the pyrolyzed samples, Figure S2: Raman spectra of the pyrolyzed and HF-etched samples, Figure S3: Differential scanning calorimetry curves of the pyrolyzed materials, Figure S4: Differential scanning calorimetry of the HF-etched samples, Figure S5: $t$ plots obtained from the nitrogen adsorption isotherms of the pyrolyzed materials, Figure S6: BJH pore size distributions of the HF-etched samples, Figure S6: XRD patterns of the HF-etched materials.

Author Contributions: Conceptualization, A.T.; methodology, A.T.; software, F.R.; validation, A.T., and F.R.; formal analysis, A.T.; investigation, F.R.; resources, F.R.; data curation, A.T.; writingoriginal draft preparation, A.T.; writing-review and editing, A.T.; visualization, A.T. and J.R.; supervision, J.R.; project administration, M.A.R.; funding acquisition, F.R. All authors have read and agreed to the published version of the manuscript. 
Funding: This research has been developed under the frame of the project MAT2016-78700-R from the Spanish Ministry of Science and Universities.

Data Availability Statement: The data presented in this study are openly available.

Conflicts of Interest: The authors declare no conflict of interest.

\section{References}

1. Zaheer, M.; Schmalz, T.; Motz, G.; Kempe, R. Polymer derived non-oxide ceramics modified with late transition metals. Chem. Soc. Rev. 2012, 41, 5102-5116. [CrossRef]

2. Babonneau, F.; Sorarú, G.D.; Thorne, K.J.; Mackenzie, J.D. Chemical characterization of Si-Al-C-O precursor and its pyrolysis. J. Am. Ceram. Soc. 1991, 74, 1725-1728. [CrossRef]

3. Suttor, D.; Kleebe, H.J.; Ziegler, G. Formation of mullite from filled siloxanes. J. Am. Ceram. Soc. 1997, 80, 2541-2548. [CrossRef]

4. Schiavon, M.A.; Gervais, C.; Babonneau, F.; Soraru, G.D. Crystallization Behavior of Novel Silicon Boron Oxycarbide Glasses. J. Am. Ceram. Soc. 2004, 87, 203-208. [CrossRef]

5. Stabler, C.; Ionescu, E.; Graczyk-Zajac, M.; Gonzalo-Juan, I.; Riedel, R. Silicon oxycarbide glasses and glass-ceramics:“All-Rounder” materials for advanced structural and functional applications. J. Am. Ceram. Soc. 2018, 101, 4817-4856. [CrossRef]

6. Zeydanli, D.; Akman, S.; Vakifahmetoglu, C. Polymer-derived ceramic adsorbent for pollutant removal from water. J. Am. Ceram. Soc. 2018, 101, 2258-2265. [CrossRef]

7. Lu, K. Porous and high surface area silicon oxycarbide-based materials-A review. Mater. Sci. Eng. R Rep. 2015, 97, 23-49. [CrossRef]

8. Colombo, P. Engineering porosity in polymer-derived ceramics. J. Eur. Ceram. Soc. 2008, 28, 1389-1395. [CrossRef]

9. Vakifahmetoglu, C.; Pippel, E.; Woltersdorf, J.; Colombo, P. Growth of One-Dimensional Nanostructures in Porous PolymerDerived Ceramics by Catalyst-Assisted Pyrolysis. Part I: Iron Catalyst. J. Am. Ceram. Soc. 2010, 93, 959-968. [CrossRef]

10. Ionescu, E.; Terzioglu, C.; Linck, C.; Kaspar, J.; Navrotsky, A.; Riedel, R. Thermodynamic control of phase composition and crystallization of metal-modified silicon oxycarbides. J. Am. Ceram. Soc. 2013, 96, 1899-1903. [CrossRef]

11. Li, N.; Cao, Y.; Zhao, R.; Xu, Y.; An, L. Polymer-derived SiAlOC ceramic pressure sensor with potential for high-temperature application. Sens. Actuators A Phys. 2017, 263, 174-178. [CrossRef]

12. Cao, Y.; Yang, X.; Zhao, R.; Chen, Y.; Li, N.; An, L. Giant piezoresistivity in polymer-derived amorphous SiAlCO ceramics. J. Mater. Sci. 2016, 51, 5646-5650. [CrossRef]

13. Ma, Q.S.; Xu, T.H. High-temperature evolution behavior of polymer-derived SiAlOC ceramics under inert atmosphere. J. Alloys Compd. 2017, 723, 17-20. [CrossRef]

14. Yu, J.; Yang, Z.; Song, Z.; Deng, K.; Ren, Z. Preparation of porous Al2O3 ceramics with in situ formed C-nanowires derived form silicone resin. Mater. Lett. 2018, 212, 271-274. [CrossRef]

15. Cao, Y.; An, L. Anomalous piezo-dielectricity of a polymer-derived amorphous silicoaluminum oxycarbide (SiAlCO). Ceram. Int. 2018, 44, 1467-1470. [CrossRef]

16. Ichikawa, H. Polymer-Derived Ceramic Fibers. In Annual Review of Materials Research; Clarke, D.R., Ed.; Annual Reviews: Palo Alto, CA, USA, 2016; Volume 46, pp. 335-356.

17. Joo, Y.J.; Kim, C.J.; Cho, K.Y. Facile synthesis and morphological study of Si-Zr-C-O fiber felts with high-thermal resistance. Ceram. Int. 2019, 45, 16008-16014. [CrossRef]

18. Macedo, H.P.; Medeiros, R.L.; Ilsemann, J.; Melo, D.M.; Rezwan, K.; Wilhelm, M. Nickel-containing hybrid ceramics derived from polysiloxanes with hierarchical porosity for CO2 methanation. Microporous Mesoporous Mater. 2019, 278, 156-166. [CrossRef]

19. Seifollahi Bazarjani, M.; Kleebe, H.-J.; Müller, M.M.; Fasel, C.; Baghaie Yazdi, M.; Gurlo, A.; Riedel, R. Nanoporous Silicon Oxycarbonitride Ceramics Derived from Polysilazanes In situ Modified with Nickel Nanoparticles. Chem. Mater. 2011, 23, 4112-4123. [CrossRef]

20. Schubert, M.; Wilhelm, M.; Bragulla, S.; Sun, C.; Neumann, S.; Gesing, T.M.; Pfeifer, P.; Rezwan, K.; Bäumer, M. The Influence of the Pyrolysis Temperature on the Material Properties of Cobalt and Nickel Containing Precursor Derived Ceramics and their Catalytic Use for CO2 Methanation and Fischer-Tropsch Synthesis. Catal. Lett. 2017, 147, 472-482. [CrossRef]

21. Scheffler, M.; Greil, P.; Berger, A.; Pippel, E.; Woltersdorf, J. Nickel-catalyzed in situ formation of carbon nanotubes and turbostratic carbon in polymer-derived ceramics. Mater. Chem. Phys. 2004, 84, 131-139. [CrossRef]

22. Vakifahmetoglu, C.; Colombo, P.; Carturan, S.M.; Pippel, E.; Woltersdorf, J. Growth of One-Dimensional Nanostructures in Porous Polymer-Derived Ceramics by Catalyst-Assisted Pyrolysis. Part II: Cobalt Catalyst. J. Am. Ceram. Soc. 2010, 93, 3709-3719. [CrossRef]

23. Abd-El-Aziz, A.S.; Agatemor, C.; Etkin, N.; Bissessur, R. Tunable room-temperature soft ferromagnetism in magnetoceramics of organometallic dendrimers. J. Mater. Chem. C 2017, 5, 2268-2281. [CrossRef]

24. Shao, G.; Liang, J.; Zhao, W.; Zhao, B.; Liu, W.; Wang, H.; Fan, B.; Xu, H.; Lu, H.; Wang, Y.; et al. Co decorated polymer-derived $\mathrm{SiCN}$ ceramic aerogel composites with ultrabroad microwave absorption performance. J. Alloys Compd. 2020, 813, 152007. [CrossRef] 
25. Fortuniak, W.; Pospiech, P.; Mizerska, U.; Chojnowski, J.; Slomkowski, S.; Nyczyk-Malinowska, A.; Wojteczko, A.; Wisla-Walsh, E.; Hasik, M. Generation of meso-and microporous structures by pyrolysis of polysiloxane microspheres and by HF etching of SiOC microspheres. Ceram. Int. 2018, 44, 374-383. [CrossRef]

26. Duan, L.; Ma, Q.; Chen, Z. Preparation and characterization of mesoporous silicon oxycarbide ceramics without free carbon from polysiloxane. J. Eur. Ceram. Soc. 2013, 33, 841-846. [CrossRef]

27. Tamayo, A.; Peña-Alonso, R.; Rubio, J.; Raj, R.; Sorarù, G.D.; Oteo, J.L. Surface Energy of Sol Gel-Derived Silicon Oxycarbide Glasses. J. Am. Ceram. Soc. 2011, 94, 4523-4533. [CrossRef]

28. Mazo, M.A.; Tamayo, A.; Rubio, J. Highly micro- and mesoporous oxycarbide derived materials from HF etching of silicon oxycarbide materials. Microporous Mesoporous Mater. 2019, 289, 109614. [CrossRef]

29. Gregg, S.J.; Sing, K.S.W. Adsorption, Surface Area and Porosity; Academic Press: London, UK, 1982; p. 303.

30. Fidalgo, A.; Ilharco, L.M. Correlation between physical properties and structure of silica xerogels. J. Non-Cryst. Solids 2004, 347, 128-137. [CrossRef]

31. Bois, L.; Maquet, J.; Babonneau, F.; Mutin, H.; Bahloul, D. Structural characterization of sol-gel derived oxycarbide glasses. 1. Study of the pyrolysis process. Chem. Mater. 1994, 6, 796-802. [CrossRef]

32. Pantano, C.G.; Singh, A.K.; Zhang, H. Silicon Oxycarbide Glasses. J. Sol.-Gel Sci. Technol. 1999, 14, 7-25. [CrossRef]

33. Almeida, R.M.; Guiton, T.A.; Pantano, C.G. Detection of LO mode in v-SiO2 by infrared diffuse reflectance spectroscopy. J. Non-Cryst. Solids 1990, 119, 238-241. [CrossRef]

34. Fidalgo, A.; Ilharco, L.M. Chemical Tailoring of Porous Silica Xerogels: Local Structure by Vibrational Spectroscopy. Chem. A Eur. J. 2004, 10, 392-398. [CrossRef] [PubMed]

35. Yoshino, H.; Kamiya, K.; Nasu, H. IR study on the structural evolution of sol-gel derived SiO2 gels in the early stage of conversion to glasses. J. Non-Cryst. Solids 1990, 126, 68-78. [CrossRef]

36. Awazu, K.; Kawazoe, H. Strained Si-O-Si bonds in amorphous $\mathrm{SiO} 2$ materials: A family member of active centers in radio, photo, and chemical responses. J. Appl. Phys. 2003, 94, 6243-6262. [CrossRef]

37. Koike, C.; Noguchi, R.; Chihara, H.; Suto, H.; Ohtaka, O.; Imai, Y.; Matsumoto, T.; Tsuchiyama, A. Infrared spectra of silica polymorphs and the conditions of their formation. Astrophys. J. 2013, 778, 60. [CrossRef]

38. Su, D.; Li, Y.-L.; An, H.-J.; Liu, X.; Hou, F.; Li, J.-Y.; Fu, X. Pyrolytic transformation of liquid precursors to shaped bulk ceramics. J. Eur. Ceram. Soc. 2010, 30, 1503-1511. [CrossRef]

39. Ruan, D.-S.; Li, Y.-L.; Wang, L.; Su, D.; Hou, F. Fabrication of silicon oxycarbide fibers from alkoxide solutions along the sol-gel process. J. Sol. Gel Sci. Technol. 2010, 56, 184-190. [CrossRef]

40. Gu, C.; Guo, C.; Dong, X.; Hu, Z.; Wu, P.; Su, Z.; Lu, Y.; Xu, B.; Yu, Z.; Liu, A. Core-shell structured iron-containing ceramic nanoparticles: Facile fabrication and excellent electromagnetic absorption properties. J. Am. Ceram. Soc. 2019, 102, 7098-7107. [CrossRef]

41. Ding, D.; Wang, J.; Xiao, G.; Li, Z.; Bai, B.; Ren, J.; He, G. Enhanced electromagnetic wave absorbing properties of Si-O-C ceramics with in-situ formed 1D nanostructures. Int. J. Appl. Ceram. Technol. 2019, 17, 734-744. [CrossRef]

42. Ferrari, A.C.; Robertson, J. Interpretation of Raman spectra of disordered and amorphous carbon. Phys. Rev. B 2000, 61, 14095. [CrossRef]

43. Schmidt, H.; Koch, D.; Grathwohl, G.; Colombo, P. Micro-/Macroporous Ceramics from Preceramic Precursors. J. Am. Ceram. Soc. 2001, 84, 2252-2255. [CrossRef]

44. Tamayo, A.; Rubio, F.; Teresa Colomer, M.; Arroyo, C.; Rodríguez, M.A. Characterization of polymer-derived ceramers subjected to wet-etching and the evolution of the carbon phase during thermal conversion. J. Non-Cryst. Solids 2020, 547, 120302. [CrossRef]

45. Erb, D.; Lu, K. Additive and pyrolysis atmosphere effects on polysiloxane-derived porous SiOC ceramics. J. Eur. Ceram. Soc. 2017, 37, 4547-4557. [CrossRef]

46. Yu, Y.; Zhang, Y.; Yang, J.; Tang, M. Synthesis and characterization of ceramic precursor aluminum-containing polycarbosilane and its pyrolysis. J. Inorg. Organomet. Polym. Mater. 2007, 17, 569-575. [CrossRef]

47. Duan, Y.; Mo, G.; Huangfu, Z.; Liang, Y.; Cui, Z.; He, L.; Huang, Z.; Chai, Z.; Huang, Q. Effects of aluminium content on the molecular structure and properties of polyaluminocarbosilane for SiC fibre fabrication. Ceram. Int. 2019, 45, 16380-16386. [CrossRef]

48. Bik, M.; Jeleń, P.; Długoń, E.; Bik, E.; Mroczka, K.; Barańska, M.; Sitarz, M. SiAlOC glasses derived from sol-gel synthesized ladder-like silsesquioxanes. Ceram. Int. 2019, 45, 1683-1690. [CrossRef]

49. Yang, J.; Cheng, X.; Yu, Y.; Zhang, Y. Quantitative determinations in the molecular structures of polyaluminocarbosilane. Polymer 2011, 52, 3811-3818. [CrossRef]

50. Padmaja, P.; Anilkumar, G.M.; Mukundan, P.; Aruldhas, G.; Warrier, K.G.K. Characterisation of stoichiometric sol-gel mullite by fourier transform infrared spectroscopy. Int. J. Inorg. Mater. 2001, 3, 693-698. [CrossRef]

51. Harshe, R.R. Synthesis and Processing of Amorphous Si (Al) OC Bulk Ceramics; Technische Universität Darmstadt: Darmstadt, Germany, 2004.

52. Li, X.; Edirisinghe, M.J. Evolution of the Ceramic Structure during Thermal Degradation of a Si-Al-C $-\mathrm{O}$ Precursor. Chem. Mater. 2004, 16, 1111-1119. [CrossRef]

53. Cao, Y.; Yang, X.; An, L. Electric conductivity and microstructure evolution of polymer-derived SiAlCO ceramics. Ceram. Int. 2016, 42, 4033-4038. [CrossRef] 
54. Dirè, S.; Ceccato, R.; Gialanella, S.; Babonneau, F. Thermal evolution and crystallisation of polydimethylsiloxane-zirconia nanocomposites prepared by the sol-gel method. J. Eur. Ceram. Soc. 1999, 19, 2849-2858. [CrossRef]

55. Ionescu, E.; Linck, C.; Fasel, C.; Muller, M.; Kleebe, H.J.; Riedel, R. Polymer-Derived SiOC/ZrO2 Ceramic Nanocomposites with Excellent High-Temperature Stability. J. Am. Ceram. Soc. 2010, 93, 241-250. [CrossRef]

56. Papet, P.; Le Bars, N.; Baumard, J.; Lecomte, A.; Dauger, A. Transparent monolithic zirconia gels: Effects of acetylacetone content on gelation. J. Mater. Sci. 1989, 24, 3850-3854. [CrossRef]

57. Ismail, H.M. Characterization of the decomposition products of zirconium acetylacetonate: Nitrogen adsorption and spectrothermal investigation. Powder Technol. 1995, 85, 253-259. [CrossRef]

58. Dirè, S.; Ceccato, R.; Babonneau, F. Structural and microstructural evolution during pyrolysis of hybrid polydimethylsiloxanetitania nanocomposites. J. Sol. Gel Sci. Technol. 2005, 34, 53-62. [CrossRef]

59. Liu, C.; Pan, R.; Hong, C.; Zhang, X.; Han, W.; Han, J.; Du, S. Effects of Zr on the precursor architecture and high-temperature nanostructure evolution of SiOC polymer-derived ceramics. J. Eur. Ceram. Soc. 2016, 36, 395-402. [CrossRef]

60. Ferrari, A.C.; Basko, D.M. Raman spectroscopy as a versatile tool for studying the properties of graphene. Nat. Nanotechnol. 2013, 8, 235-246. [CrossRef] [PubMed]

61. Pereira, J.L.; Godoy, N.V.; Ribeiro, E.S.; Segatelli, M.G. Synthesis and structural characterization of hybrid polymeric networksderived-SiCxOy in the presence and absence of cobalt acetate. J. Anal. Appl. Pyrolysis 2015, 114, 11-21. [CrossRef] 